\title{
Active management in patients with ocular manifestations of myasthenia gravis
}

\begin{abstract}
Purpose Myasthenia gravis can cause variable strabismus with disabling diplopia and/or poor cosmesis. A retrospective study of a group of patients with myasthenia gravis or 'myasthenia gravis like' syndromes was made. Methods The study group consisted of patients who had undergone botulinum toxin treatment and/or surgery for disabling diplopia, poor cosmesis or both. Surgical treatment was by conventional techniques including recess/resect, posterior fixation, superior oblique tenotomy and adjustable sutures.

Results There were 9 patients in the study group (8 female, 1 male). Age at surgery ranged from 21 to 59 years (mean 46 years). Six were symptom-free following treatment. Two, although symptomatically improved, had occasional diplopia. One patient failed treatment and required an occlusive contact lens.

Conclusions The ocular manifestations of myasthenia gravis or 'myasthenia gravis like' syndromes may respond to surgery and/or botulinum toxin injection. Active intervention should be considered when deviations become stable. To our knowledge this is the first report of the use of botulinum toxin in such patients.
\end{abstract}

Key words Botulinum toxin, Extraocular muscle surgery, Myasthenia gravis

Myasthenia gravis is the result of an antibodymediated autoimmune attack on acetylcholine receptors at the neuromuscular junction. ${ }^{1}$

C.R. Bentley

E. Dawson

J.P. Lee

Moorfields Eye Hospital

London, UK

Mr J.P. Lee, FRCS,

FRCOphth

Moorfields Eye Hospital

NHS Trust

City Road

London EC1V 2PD, UK

Received: 15 February 2000

Accepted in revised form:

28 July 2000
CHRISTOPHER R. BENTLEY,

In our experience surgery and botulinum toxin chemodenervation either individually or in combination have a role to play in this difficult clinical scenario of the symptomatic patient who has been stable for a minimum of 6 months, and there is a small literature to support this. $^{4-7}$

Our aim was to study, partly retrospectively, a group of patients with myasthenia gravis or myasthenia gravis like syndromes who had undergone extraocular muscle surgery and/or botulinum toxin treatment.

\section{Materials and methods}

The study group consisted of patients identified from a large botulinum toxin database $(>4000$ cases) and/or the specialised motility clinic records of a single surgeon (J.P.L.). Five cases (Table 1) had a clinical diagnosis of myasthenia gravis confirmed by either tensilon testing and/ or the presence of anti-acetylcholine receptor antibodies. Two cases were referred with a diagnosis of myasthenia gravis and were or had been on systemic treatment for this. The remaining cases (nos. 5 and 7) were diagnosed on clinical grounds based on a combination of ocular and previous systemic symptoms representing 'pseudo-myasthenia', so called because they had all the features of clinical myasthenia but exhaustive investigation had proved inconclusive. The patients were assessed orthoptically and clinically to confirm oculomotor stability (static angle and Hess test) for a minimum of 6 months (Table 1). All had undergone botulinum toxin treatment and/or surgery for disabling diplopia, poor cosmesis o both, at a single tertiary referral centre. All patients were free from systemic symptoms at the time of treatment. All individuals had had pyridostigmine, except cases 6 and 8 who werd treated with prednisolone, prior to our intervention. Five patients remained on systemic treatment under the supervision of their neurologist. Surgical treatment was by conventional recession and resection procedures, with adjustable suture technique, superior oblique tenotomy and posterior fixation suture where necessary. 


\begin{tabular}{lccccc}
\hline Patient no./Sex & $\begin{array}{c}\text { Age at presentation } \\
\text { (years) }\end{array}$ & $\begin{array}{c}\text { Stability prior to treatment } \\
\text { (years) }\end{array}$ & Thymectomy & ACh antibodies & Tensilon test \\
\hline $1 / \mathrm{F}$ & 11 & 1 & Yes & Unknown & +ve \\
$2 / \mathrm{F}$ & 49 & 5 & No & +ve & Equivocal \\
$3 / \mathrm{F}$ & 14 & 2 & Yes & Unknown & N/A \\
$4 / \mathrm{M}$ & 47 & 4 & No & -ve & N/A \\
$5 / \mathrm{F}$ & 20 & 1.5 & No & -ve & Equivocal \\
$6 / \mathrm{F}$ & 50 & 2 & No & Unknown & +ve \\
$7 / \mathrm{F}$ & 20 & 2.5 & Yes & Unknown & N/A \\
$8 / \mathrm{F}$ & 32 & 4 & Yes & + ve & + ve \\
9/F & 35 & 3 & No & -ve & + ve \\
\hline
\end{tabular}

\section{Results}

There were nine patients in the study group ( 8 female; 1 male). Age at presentation ranged from 21 to 59 years (mean 46 years). The study group divided conveniently into three treatment groups, namely toxin only (3 cases), surgery only (3 cases) and combined toxin and surgery (3 cases).

In the toxin only group, 2 patients were symptom-free with maintenance injections of botulinum toxin. The interval between treatments varied between 6 and 12 months. One patient, despite repeated injections, could not achieve satisfactory alignment and declined surgery. To relieve disabling diplopia she was fitted with an occlusive contact lens. Three patients underwent surgery alone; 1 of these was symptom free post-operatively, while 2 patients required a prism for control. The 3 remaining patients required a combination of surgery and toxin injections. Of these, 1 patient was satisfactorily aligned while 2 had occasional diplopia but were symptomatically improved. In all cases follow-up was for a minimum of 6 months (mean follow-up 20 months after treatment). The cases are summarised in the Tables 1 and 2. Cases 4 and 6 are described in more detail below.

\section{Case reports}

Case 4 was a 56-year-old man who originally presented in 1989 with bilateral fatiguable ptosis most marked at the end of the day. He underwent thymectomy in 1990 with some improvement of his systemic symptoms and was maintained on pyridostigmine $60 \mathrm{mg}$ daily. In the past he had been tried on azathioprine but this had been discontinued following an adverse haematological disturbance. At the time of referral he had a marked left inferior rectus underaction giving diplopia on depression. Pre-operatively he measured 18 prism dioptres of left hypertropia near and distance. Following left superior rectus recession of $4 \mathrm{~mm}$ he was symptomfree with 2 prism dioptres of left hyperphoria for near and 3 prism dioptres of left hyperphoria for distance. With this new ocular position he achieved stereopsis of 55 seconds of arc. The pre- and post-operative Hess charts are shown in Fig. 1.

Case 6 was a 55-year-old woman who presented with a 10 year history of vertical diplopia and fatiguable ptosis. Previously she had some evening fatiguability but at the time of surgery she had been free of systemic symptoms for upwards of 18 months. Her diplopia was initially controlled with prisms but with increasing

Table 2. Summary of ocular motility findings and surgical procedures

\begin{tabular}{|c|c|c|c|c|c|c|}
\hline $\begin{array}{l}\text { Patient } \\
\text { no. }\end{array}$ & $\begin{array}{l}\text { Pre-operative } \\
\text { alignment } \\
\text { (PDs) }\end{array}$ & Procedure & $\begin{array}{l}\text { Final alignment } \\
\text { (PDs) }\end{array}$ & $\begin{array}{l}\text { Post-operative } \\
\text { BSV (s/arc) }\end{array}$ & $\begin{array}{l}\text { Follow-up } \\
\text { (months) }\end{array}$ & Comments \\
\hline 1 & Exo 40 & RLR BTXA $\times 3$ & Exo 2 & 100 & 12 & Symptom-free ${ }^{a}$ \\
\hline 2 & Eso $>90 \mathrm{R} / \mathrm{L} 12$ & RMR BTXA $\times 3$ & Eso 25 R/L 6 & Nil & 6 & $\begin{array}{l}\text { Diplopia; } \\
\text { occlusive contact lens }\end{array}$ \\
\hline 3 & Exo 45 L/R 18 & RLR/LLR BTXA & Exo 14 L/R 10 & Weak & 60 & Symptom-free ${ }^{a}$ \\
\hline 4 & L/R 18 & LSR $-4 \mathrm{~mm}$ & Exo 2 & 55 & 24 & Symptom-free \\
\hline 5 & Exo 8 L/R 34 & $\begin{array}{l}\text { i) LIO disinsertion } \\
\text { ii) RIR -5, LIR }-3.5 \\
\text { iii) R Knapp }\end{array}$ & Exo 6 R/L 11 & 40 & 24 & $\begin{array}{l}\text { Symptom-free } \\
\text { (with prism) }\end{array}$ \\
\hline 6 & Exo 6 L/R 20 & $\mathrm{~L}$ inverse Knapp & Exo 2 L/R 4 & 100 & 6 & Symptom-free \\
\hline 7 & Exo 60 L/R 20 & $\begin{array}{l}\text { i) LLR BTXA } \\
\text { ii) RLR }-9 \text {, RMR }+10\end{array}$ & Exo 4 L/R 16 & Nil & 14 & Occasional diplopia \\
\hline 8 & Exo 65 L/R 4 & $\begin{array}{l}\text { i) RLR -7, RMR +6, LLR -6 } \\
\text { ii) BTXA RLR }\end{array}$ & Eso 4 L/R 5 & Nil & 27 & Occasional diplopia \\
\hline 9 & Eso $25 \mathrm{~L} / \mathrm{R} 7$ & $\begin{array}{l}\text { i) LMR BTXA } \\
\text { ii) LMR }-5, \text { LLR +5 }\end{array}$ & Eso 2 L/R 2 & 60 & 10 & Symptom-free \\
\hline
\end{tabular}

BSV, binocular single vision; R, right; L, left; BTXA, botulinum toxin; LR, lateral rectus; MR, medial rectus; SR, superior rectus; IR, inferior rectus; $\mathrm{IO}$, inferior oblique.

${ }^{-}$With maintenance toxin. 

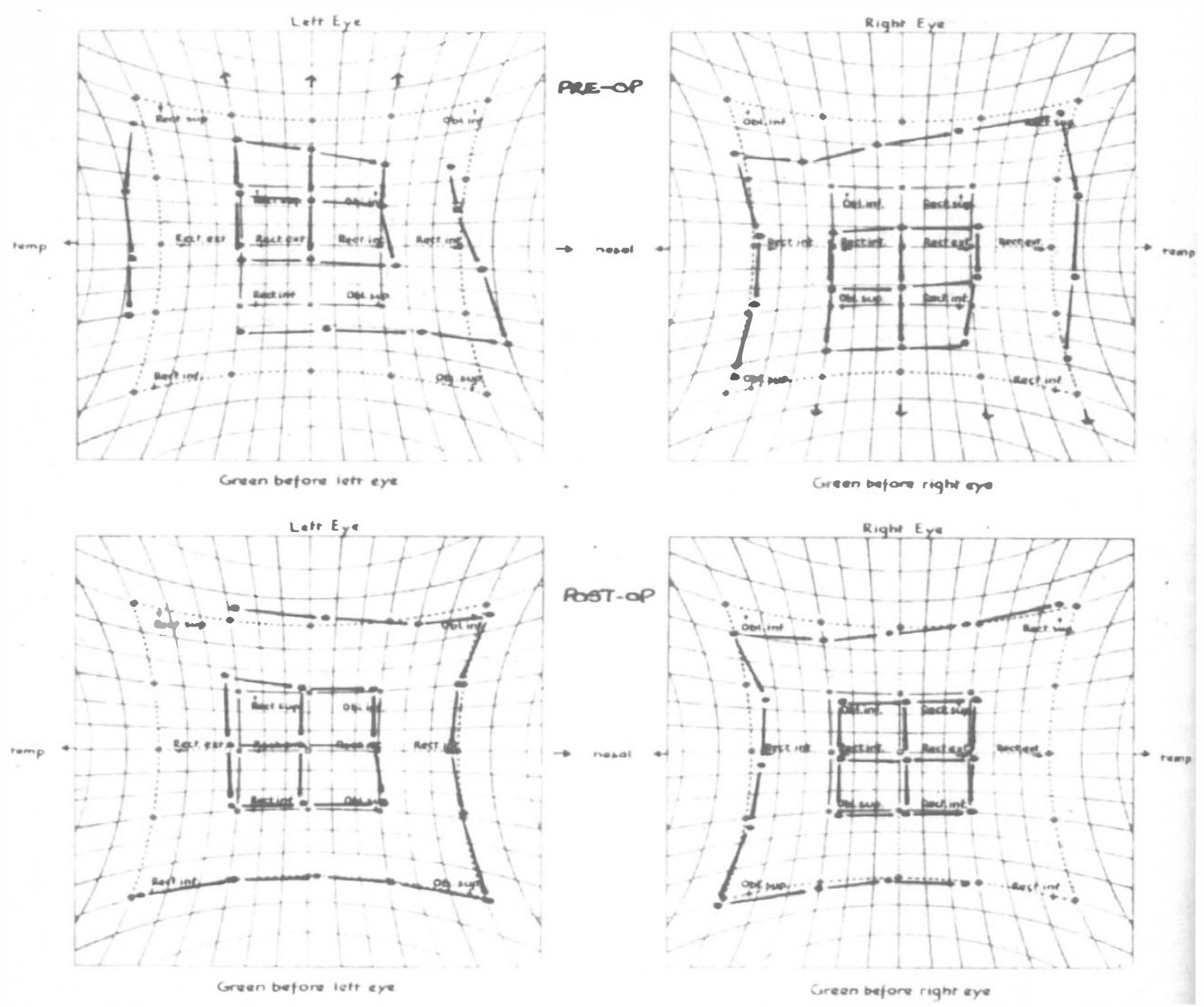

Fig. 1. Case 4. Pre- and post-operative Hess charts following left superior rectus recession.

disease activity an occlusive contact lens had been fitted. This approach had limited success for 5 years. Her symptoms were improved with pyridostigmine; however, this was not tolerated due to a previous ileostomy for severe ulcerative colitis. At the time of referral she had a left hypertropia of 20 prism dioptres at near and 18 prism dioptres for distance, with associated left inferior rectus underaction. A left inverse Knapp procedure was performed, following which she had a left hyperphoria of 4 prism dioptres for near and 2 prism dioptres for distance (her pre- and post-operative appearance is shown in Fig. 2). This realignment resulted in an asymptomatic patient with stereopsis of 100 seconds of arc at her first post-operative visit. Following her most recent assessment she required a small prism and was asymptomatic with good control.

\section{Complications}

Botulinum toxin injections are not free from side-effects. This was demonstrated in case 3. This 57-year-old woman was diagnosed with myasthenia gravis at the age of 14 years. Her generalised weakness was relatively well controlled on pyridostigmine. Her ocular status pre- operatively was a decompensating exophoria of 45 prism dioptres with left hyperphoria of 18 prism dioptres for near and distance. She underwent right inferior rectus and bilateral lateral rectus botulinum toxin injections under electromyographic control. Following this she maintains good control of an exophoria which measures 10 and 4 prism dioptres base in, near and distance respectively, with a small left hyperphoria. She continues to be satisfactorily controlled with maintenance toxin injections to both lateral recti at 6 monthly intervals. Following her most recent treatment with toxin she developed a left ptosis with an associated left hypotropia which resolved within 3 months.

Systemic treatment remained unchanged following our interventions in all patients.

\section{Discussion}

It is apparent from the small numbers generated by our research of a large database that extraocular muscle surgery and/or botulinum toxin therapy is not appropriate in most cases where continued disease activity exists. It is of interest that Oosterhuis, ${ }^{8}$ in a study of 58 myasthenics, found more than $50 \%$ of long-term 


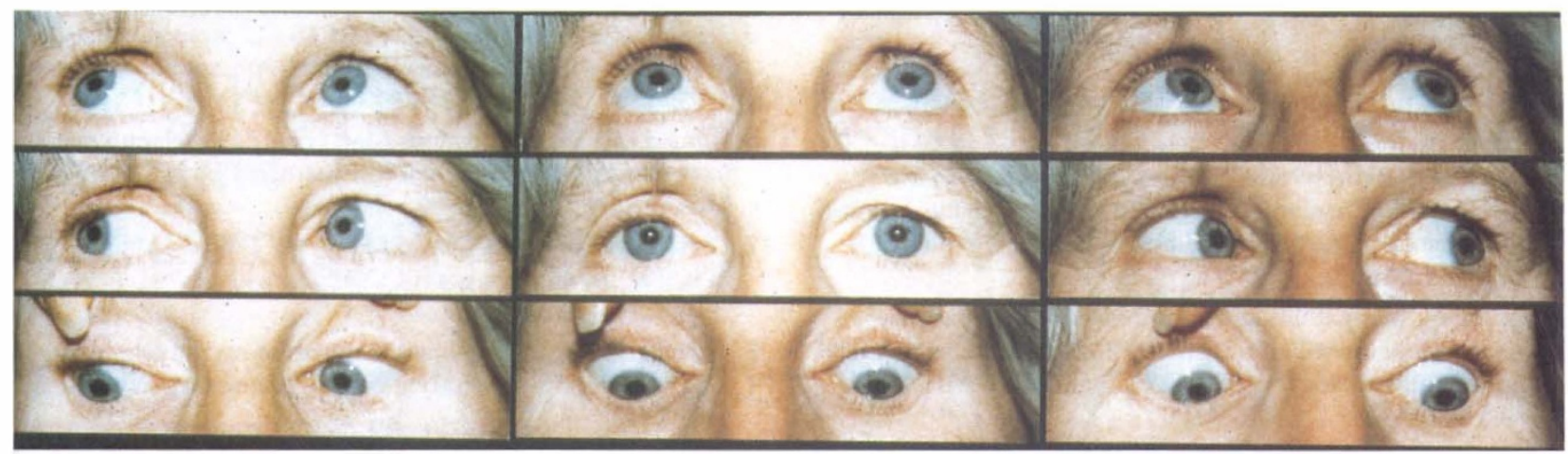

(a)

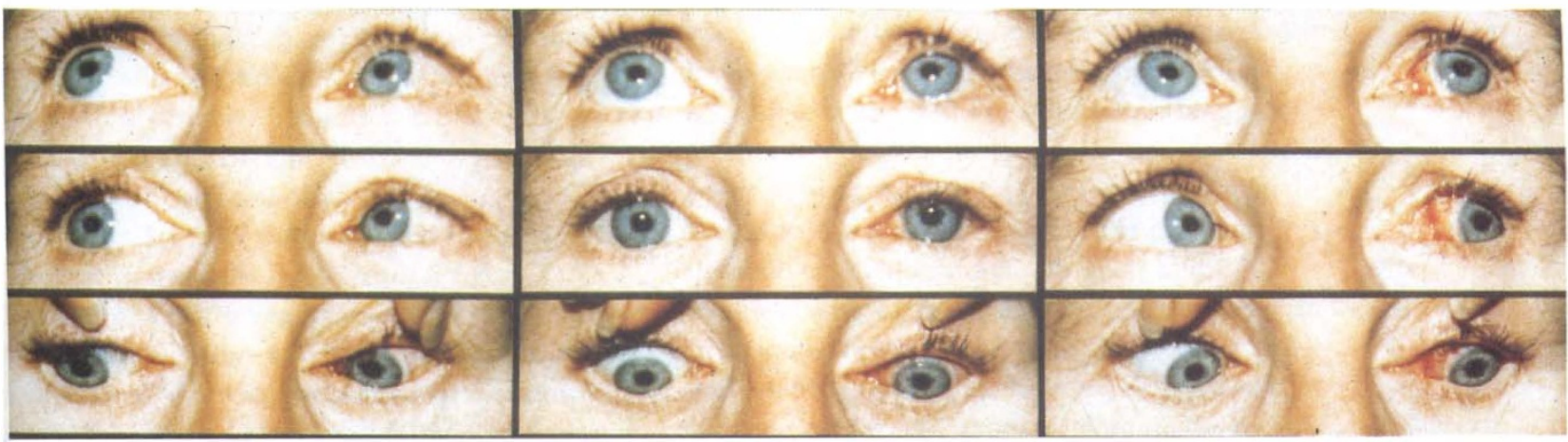

(b)

Fig. 2. Case 6. Pre- and post-operative appearance following left inverse Knapp procedure.

survivors were in remission. Not surprisingly then, there appears to be a small subgroup of myasthenics who had a stable oculomotor problem leaving open options for non-systemic treatments. Acheson and co-workers ${ }^{4}$ described 5 cases ranging from age 16 to 52 years with a 4:1 male preponderance, all positive for acetylcholine receptor antibodies. All their cases had been stable for at least 2 years prior to surgery and had constant diplopia. Four of these five cases were exotropic prior to surgery. They described mainly horizontal rectus recess/resect procedures with superior oblique posterior tenotomy in 2 cases. Follow-up was from 6 months to 6 years, and all patients were described as having a significantly increased field of binocular single vision. A similar group was reported by Davidson et al., ${ }^{5}$ who described 6 cases with a clinical diagnosis of myasthenia who had been stable for approximately 5 months prior to surgery. This group is interesting as it included 2 children (aged 4 and 7 years). The 4 adults had moderate limitation of adduction and all patients were exotropic. Their mean follow-up was 44 months, minimum was 7 months. Davidson et al. described mainly horizontal recess/resect procedures with some supramaximal $(7-10 \mathrm{~mm})$ recessions on adjustable sutures where required and two superior oblique tenotomies. Hamed et al. ${ }^{6}$ reviewed 4 cases with myasthenia based on clinical grounds and a positive tensilon test (anti-acetylcholine receptor antibodies were not detected in any of their cases). Three of their four cases were exotropic and all underwent horizontal recess/resect procedures with reported improvement of both ocular alignment and diplopic symptoms in all cases. One case was noted to have recurrent exotropia within 2.5 years. The only remaining paper, that we are aware of, on this topic is that by Ohtsuki and co-workers, ${ }^{7}$ who operated on 4 patients and had good results in 3 . They made electron microscopic studies of resected muscles and noted non-specific degenerative changes and sarcomeric disorganisation compared with controls.

This literature review thus includes 19 cases where surgical intervention has been reported in patients with stable ocular motility signs with varying degrees of success. In this series we have added 9 further cases managed both surgically and with botulinum toxin. Our success rates compare favourable with those reported above. It is apparent from our use of botulinum toxin that it has a role to play in the treatment of ocular myasthenia and to our knowledge this has not been previously reported.

Myasthenia gravis and its treatment is a topic of intense research, particularly in the area of cell-mediated autoimmunity. We look forward to a time when systemic therapy will help these patients, perhaps avoiding surgery altogether. ${ }^{9}$

\section{Summary}

From our data patients with myasthenia gravis and stable ocular motility signs should be considered for active management, namely botulinum toxin, muscle surgery or a combination of both.

We are grateful to Miss G. W. Adams for the opportunity to report one of her cases. 


\section{References}

1. Seybold ME. Myasthenia gravis: a clinical and basic science review. JAMA 1983;250:2516-21.

2. Glaser JS, Siatkowski RM. Infranuclear disorders of eye movement. In: Tasman W, Jaeger EA, editors. Duane's clinical ophthalmology, vol 2. Philadelphia: Lippincott Williams \& Wilkins, 1998:36.

3. Miller NR. Myopathies and disorders of neuro-muscular transmission. In: Miller NR, editor. Walsh and Hoyt's clinical neuro-ophthalmology, vol 2. 4th ed. Baltimore: Williams \& Wilkins, 1985:859.

4. Acheson JF, Elston JS, Lee JP, Fells P. Extraocular muscle surgery in myasthenia gravis. Br J Ophthalmol 1991;75:232-5.
5. Davidson JL, Rosenbaum AL, McCall LC. Strabismus surgery in patients with myasthenia. J Pediatr Ophthalmol Strabismus 1993;5:292

6. Hamed LF, Challa P, Fanous MM, Guy JR. Strabismus surgery in selected patients with stable myasthenia gravis. Bin Vis Eye Muscle Surg 1994;9:283-90.

7. Ohtsuki H, Hasebe S, Okano M, Furuse T. Strabismus surgery in ocular myasthenia gravis. Ophthalmologica 1996;210:95-100.

8. Oosterhuis HJGH. The natural course of myasthenia gravis: a long term follow up study. J Neurol Neurosurg Psychiatry 1989;52:1121-7.

9. Drachman DB, Targeting T cells in myasthenia gravis. Ann Neurol 1999;46:553-5. 